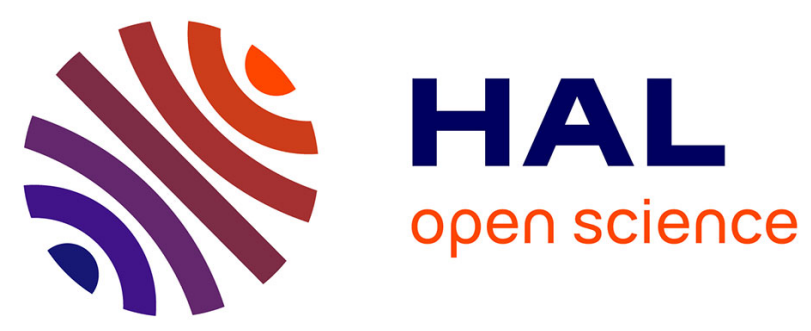

\title{
Stemness markers characterize IGR-CaP1, a new cell line derived from primary epithelial prostate cancer
} Anne Chauchereau, Nader Al Nakouzi, Catherine Gaudin, Sylvestre Le Moulec, Daniel Compagno, Nathalie Auger, Jean Bénard, Paule Opolon, François Rozet, Pierre Validire, et al.

\section{To cite this version:}

Anne Chauchereau, Nader Al Nakouzi, Catherine Gaudin, Sylvestre Le Moulec, Daniel Compagno, et al.. Stemness markers characterize IGR-CaP1, a new cell line derived from primary epithelial prostate cancer. Experimental Cell Research, 2011, 317 (3), pp.262-275. 10.1016/j.yexcr.2010.10.012 . hal03211032

\section{HAL Id: hal-03211032 \\ https://hal.science/hal-03211032}

Submitted on 28 Apr 2021

HAL is a multi-disciplinary open access archive for the deposit and dissemination of scientific research documents, whether they are published or not. The documents may come from teaching and research institutions in France or abroad, or from public or private research centers.
L'archive ouverte pluridisciplinaire HAL, est destinée au dépôt et à la diffusion de documents scientifiques de niveau recherche, publiés ou non, émanant des établissements d'enseignement et de recherche français ou étrangers, des laboratoires publics ou privés. 


\title{
Research Article
}

\section{Stemness markers characterize IGR-CaP1, a new cell line derived from primary epithelial prostate cancer}

\author{
Anne Chauchereau ${ }^{a, h, *}$, Nader Al Nakouzi ${ }^{a, h}$, Catherine Gaudin ${ }^{a, h}$, Sylvestre Le Moulec $^{a, h}$, \\ Daniel Compagno ${ }^{b}$, Nathalie Auger ${ }^{c, h}$, Jean Bénard ${ }^{c, h}$, Paule Opolon ${ }^{d, h}$, François Rozet ${ }^{e}$, \\ Pierre Validire ${ }^{f}$, Gaëlle Fromont ${ }^{g}$, Karim Fizazi ${ }^{a, h}$ \\ a Prostate Cancer Group, INSERM U981, Institut Gustave Roussy, Villejuif, F-94805, France \\ ${ }^{\mathrm{b}}$ Laboratory of Prostate Cancer, Dep. Química Biológica-University of Buenos-Aires-FCEyN, Buenos-Aires, Argentina \\ ${ }^{\mathrm{C}}$ Department of Medical Biology and Pathology, Institut Gustave Roussy, Villejuif, F-94805, France \\ dUMR8121, Institut Gustave Roussy, Villejuif, F-94805, France \\ e Department of Urology, Institut Mutualiste Montsouris, Paris, F-75014, France \\ f Department of Pathology, Institut Mutualiste Montsouris, Paris, F-75014, France \\ ${ }^{\mathrm{g}}$ Department of Pathology, CHU-University of Poitiers, Poitiers, F-86000, France \\ ${ }^{\mathrm{h}}$ University Paris-Sud 11, France
}

\section{A R T I C L E I N F O R M A T I O N}

Article Chronology:

Received 12 April 2010

Revised version received

20 September 2010

Accepted 16 October 2010

\section{Keywords:}

Prostatic neoplasms

Tumor cells cultured

Basal epithelial cells

Tumor stem cells

Gene expression profiling

\begin{abstract}
A B S T R A C T
Deciphering molecular pathways involved in the early steps of prostate oncogenesis requires both in vitro and in vivo models derived from human primary tumors. However the few recognized models of human prostate epithelial cancer originate from metastases. To date, very few models are proposed from primary tumors and immortalizing normal human prostate cells does not recapitulate the natural history of the disease. By culturing human prostate primary tumor cells onto human epithelial extra-cellular matrix, we successfully selected a new prostate cancer cell line, IGR-CaP1, and clonally-derived subclones. IGR-CaP1 cells, that harbor a tetraploid karyotype, high telomerase activity and mutated TP53, rapidly induced subcutaneous xenografts in nude mice. Furthermore, IGR-CaP1 cell lines, all exhibiting negativity for the androgen receptor and PSA, express the specific prostate markers alpha-methylacyl-CoA racemase and a low level of the prostate-specific membrane antigen PSMA, along with the prostate basal epithelial markers CK5 and CK14. More importantly, these clones express high CD44, CD133, and CXCR4 levels associated with high expression of $\alpha 2 \beta 1$-integrin and Oct 4 which are reported to be prostate cancer stemness markers. RT-PCR data also revealed high activation of the Sonic Hedgehog signalling pathway in these cells. Additionally, the IGR-CaP1 cells possess a 3D sphere-forming ability and a renewal capacity by maintaining their CSC potential after xenografting in mice. As a result, the hormone-independent IGR-CaP1 cellular clones exhibit the original features of both basal prostate
\end{abstract}

\footnotetext{
* Corresponding author. Prostate Cancer Group, INSERM U981, Institut Gustave Roussy, 114 rue Edouard Vaillant, Villejuif, F-94805, France. Fax: + 33142 116094.

E-mail addresses: anne.chauchereau@igr.fr (A. Chauchereau), nader.nakouzi@igr.fr (N. Al Nakouzi), catherine.gaudin@igr.fr (C. Gaudin), sylvestre.lemoulec@gmail.com (S. Le Moulec), danielcompagno@qb.fcen.uba.ar (D. Compagno), nathalie.auger@igr.fr (N. Auger), jean.benard@igr.fr (J. Bénard), paule.opolon@igr.fr (P. Opolon), francois.rozet@imm.fr (F. Rozet), pierre.validire@imm.fr (P. Validire), g.fromont@chu-poitiers.fr (G. Fromont), karim.fizazi@igr.fr (K. Fizazi).
}

0014-4827/\$ - see front matter @ 2010 Published by Elsevier Inc. doi:10.1016/j.yexcr.2010.10.012 
tissue and cancer stemness. Tumorigenic IGR-CaP1 clones constitute invaluable human models for studying prostate cancer progression and drug assessment in vitro as well as in animals specifically for developing new therapeutic approaches targeting prostate cancer stem cells.

(c) 2010 Published by Elsevier Inc.

\section{Introduction}

Prostate cancer is the second leading cause of cancer-related deaths in men in North America and Europe. Nowadays, there is still no cure available for patients with advanced disease especially when hormone independence emerges [1]. Cell cultures established directly from primary tumors from patients are powerful research resources for studying cancer cell biology and for developing new strategies against cancer. However, human prostate cells are known to be one of the most difficult tissues to develop in a continuously growing culture especially while maintaining hormone dependency. Most in vitro or xenografted models of prostate cancer have been established from metastases $[2,3]$. The immortalization of normal human prostate cells, either epithelial or stromal, has been proposed to extensively investigate the early genetic events that give rise to epithelial prostate cancer progression. However, to date, these artificial models have been unable to identify the cells that initiate prostate cancer. Clearly, due to difficulties inherent to in vitro culture, models directly derived from primary tumors are still lacking. In spite of huge efforts, only two continuously cultured human primary epithelial prostate cancer cell lines have been established, the E006AA [4] and the HH870 [5] cell lines but they have not been documented so far, except for a recent study of AR signalling in the E006AA cell line [6]. A third human prostate cancer model was recently established in vitro from a trans-rectal prostate needle biopsy specimen but it was unable to grow in nude mice [7]. Currently, prostate cancer models, directly derived from primary tumors, enabling both in vivo and in vitro approaches and representing the early stages of this cancer are still lacking.

Regarding homeostasis of prostate tumor cells, there is mounting evidence that prostate cancer results from a hierarchical model originating from rare cancer stem cells (CSC) that enables tumor maintenance [8]. Based on this model, it has been suggested that androgen-independent stem cells give rise to two types of cells, stem cells and androgen-independent transit-amplifying cells, capable of differentiating into luminal cells. Prostate cancer stem/progenitor cells may exhibit similar characteristics to those of normal stem cells likely localized in the basal cell compartment [9]. Collins et al. [10] first identified and isolated prostate stem cells from primary tumors. It was subsequently shown that these cells express CD44, $\alpha 2 \beta 1$-integrin and CD133, normal prostate epithelial stem cell markers $[11,12]$. Recently, telomerase-immortalized basal prostate epithelial cell (HPET) lines were obtained which provide a constant supply of cells while simultaneously maintaining the differentiation characteristics of the original tissue [13]. Clonally-derived HPET cells reconstitute the original human tumor in vivo and differentiate into the three prostate epithelial cell lineages, indicating a common stem/progenitor cell [14]. More recently, prostatic epithelial RC-165N/hTERT cells were obtained which exhibit a stable stem cell phenotype $\mathrm{CD} 133^{+} / \mathrm{CD}_{4} 4^{+} /$ $\alpha 2 \beta 1^{+} / 34 \beta E 12^{+} / \mathrm{CK}_{18}{ }^{+} / \mathrm{p} 63^{-} / \mathrm{AR}^{-} / \mathrm{PSA}^{-}$and the ability to differentiate into AR-positive cell types in vitro $[15,16]$. Most of these cancer stem cells were identified using surface markers that 109 recognize their corresponding normal tissue stem and progenitor 110 cells, thus strengthening the resemblance between tumor develop- 111 ment and normal prostate organogenesis. Until now, these markers 112 essentially pinpoint cell populations with CSC characteristics. 113

Here, we describe the establishment and characterization of a 114 new prostate cancer cell line and cell-derived clones from a 115 primary tumor. These cells show phenotypic features of prostate 116 epithelial basal cells, exhibit the original features of prostate tissue 117 and retain cancer stem cell properties. Thus, our new IGR-CaP1 118 models may help develop new therapeutic approaches that target 119 prostate cancer stem cells.

\section{Materials and methods}

\section{Primocultures and cell cultures}

After mechanical dissociation of human prostate tumor tissue and 124 counting, cells were seeded on an extracellular matrix (ECM) of 125 human epithelial origin, IGR-XC, and further cultured in RPMI 126 medium supplemented with 10\% FBS (foetal bovine serum, 127 Gibco), penicillin-streptomycin antibiotics and fungizone. This 128 human ECM, developed at the Institut Gustave Roussy, Villejuif, 129 France (IGR-XC, US patent 7,476,496), prevents anoikis and 130 enables epithelial cells to anchor onto the substrate [17]. 131 Primoculture conditions combined IGR-XC ECM and proline- 132 depleted RPMI medium to prevent fibroblast contamination [18]. 133 The cells were incubated at $37{ }^{\circ} \mathrm{C}$ with $5 \% \mathrm{CO}_{2}$ until they reached 134 semi-confluence and were then trypsinized. After maintaining 135 these culture conditions for 20 passages, cells were allowed to 136 grow onto plastic flasks in regular RPMI medium containing $10 \% \quad 137$ FBS and antibiotics. The renowned prostate cancer cell lines 138 LNCaP and PC3 were cultured in RPMI-1640 containing 10\% FBS 139 and MDA-PCa-2b cells, as previously described [19]. To re- 140 establish in vitro cultures after xenografting into nude mice, 141 xenografted tumors $(n=5)$ were collected when they attained 142 $300 \mathrm{~mm}^{3}$. Tumor cells were dissociated by a 30 min digestion at 143 $37^{\circ} \mathrm{C}$ with Collagenase H/DNAse I (Roche) in culture medium, as 144 previously described [20] and plated in 6-well cell culture dishes 145 in classic culture medium. Forty-eight hours after, the medium 146 was replaced by proline-depleted RPMI medium and cells were 147 cultured for 5 passages.

\section{Clinical summary}

The prostate primary tumour samples were collected from the 150 Institut Mutualiste Montsouris (Paris, France) from 3 patients in 151 accordance with protocols approved by the local ethics commit- 152 tees. The prostate cancer tissue that yielded the IGR-CaP1 cell line 153 was obtained from a 58-year-old Caucasian French patient who 154 had undergone a radical prostatectomy for clinically localized 155 prostate cancer. At diagnosis, the serum PSA level was $5.6 \mathrm{ng} / \mathrm{ml} .156$ 
Pathological analysis of the prostatectomy specimen revealed a massive bilateral posterior tumor confined to the prostatic capsule which was a moderately-differentiated adenocarcinoma with a Gleason score of 7 [4(70\%) $+3(30 \%)]$. The clinical stage assigned was pT2c Nx.

\section{Cell growth kinetics}

Cell growth kinetics was determined by counting the number of viable cells at regular intervals. After seeding in triplicate at 4000 cells/well in 12-well plates in normal culture medium or in medium containing 10\% charcoal-stripped FBS, cells were trypsinized daily, stained with trypan blue and counted. The doubling time was calculated from the regression equation of the curve. For the hormone-dependent growth assay, cells were seeded at 10000 cells/well in 96-well plates. After $24 \mathrm{~h}$, the culture medium was replaced with phenol red-free medium containing $10 \%$ charcoalstripped FBS and dihydrotestosterone (DHT) was added or not, at a final concentration of $10^{-9} \mathrm{M}$. The medium was replaced each day. After 72 h, cell survival was measured with the WST1 test (Roche).

\section{Telomerase assay}

Telomerase activity was measured by using the Biomax Telomerase detection kit (Biomax Inc., MD, US) based on a quantitative real-time telomeric repeat amplification protocol, according to the manufacturer's recommendations. Telomerase activity was determined through its ability to synthesize telomeric repeats onto an oligonucleotide substrate in cellular extracts and the resulting extended products were amplified by PCR (35-40 cycles) using the DNA SYBR Green fluorochrome and measured on a 7900HT Fast Real-Time PCR System (Applied Biosystems). Telomerase activity was quantified according to the manufacturer's recommendations against a standard curve that had an $R^{2}$ of 0.98 .

\section{DNA sequencing for analysis of TP53 mutation}

Sequencing was performed from cDNA as previously described [21]. Two different DNA preparations obtained from different cell aliquots showed the same Tp53 mutation.

\section{Karyotype}

Metaphases were harvested after a 2.5-h colchicine block. Chromosome spreads were obtained according to previously described techniques [22]. Karyotypes were established on more than 10 metaphases after R-banding according to the standardized human karyotype.

\section{Short tandem repeat DNA typing (STR typing)}

Genomic DNA extracted from the cells was prepared using the QIAamp DNA Micro kit (Qiagen) and was quantified using realtime PCR technology. The short tandem repeat (STR) analysis was conducted using the multiplex-PCR-based Identifiler amplification kit (Applied Biosystems) on $1 \mathrm{ng}$ of genomic DNA in which 16 STR loci were simultaneously co-amplified. Automated DNA fragment analysis was performed on an ABI3130xl Genetic Analyser. Fluorescent data were collected and analyzed using GeneMapper 3.2 ID-specific genotyping software (Applied Bio- systems). The resulting profile showed the assigned allele values 207 corresponding to the number of repeat units identified for each 208 locus.

\section{In vivo tumorigenicity assay}

Six-week-old male athymic nude mice (NC-nu/nu) (Janvier, 211 France) were used in conformity with the Guidelines of the French 212 Government regarding operative procedures and animal care. IGR- 213 CaP1 cells $\left(10^{7}\right)$ were subcutaneously injected into the dorsal side 214 without matrigel. Orthotopic injections were performed, as 215 previously described [23]. Briefly, the prostate of each anesthe- 216 tized mouse was exposed via a midline laparotomy incision and 217 $10^{6}$ cells in $5 \mu \mathrm{l}$ PBS were directly injected into the prostate.

\section{Western blot analysis}

Western Blot assays were performed on $50 \mu \mathrm{g}$ of whole cellular 220 lysates. Blots were probed with anti-AR (N-20) or anti-PSA 221 antibody (C-19) from SantaCruz, or anti-Oct4 antibody (Chemi- 222 con). Immunoblot analyses were developed using the enhanced 223 chemoluminescence-based detection kit (Pierce).

FACS analysis was used to determine differentiation marker 226 expression and to sort cells. For cytoplasmic or nuclear proteins, 227 permeabilization in $0.25 \%$ triton X-100 was performed before 228 labelling. The following antibodies were used: anti-human 229 EpCAM-PE (clone EBA-1, Becton Dickinson), PSMA-FITC (clone 230 107-1A4, MBL medical), CK5/8-FITC (clone 5F173, US-Biological), 231 CK8-FITC (clone B22.1, GeneTex), CK14-FITC (clone 2Q1030, US- 232 Biological), CK18-FITC (abcam), CD24-FITC (clone ML-5, BD 233 pharmingen), CD44-FITC (clone G44-26, BD Biosciences), CD133- 234 APC (AC133, Miltenyi-Biotec), CXCR4-PE (also named CD184-PE, 235 clone 12G5, BD Biosciences), P504S (AMACR) (2A10F3, Santa 236 Cruz). The corresponding isotype control antibodies were included 237 in each staining condition. For indirect labelling, purified mouse 238 $\operatorname{IgG} 2 \mathrm{~b}$ and rabbit IgG (R\&D System) were used as isotype controls 239 and Molecular Probes' Alexa Fluor 488 (1:200) were used as 240 secondary antibodies. Samples were analyzed with the FACS 241 Calibur cytometer (Becton Dickinson).

TaqMan real-time quantitative reverse transcription-PCR 243 analysis

Total RNA was extracted from cell lines using the RNeasy Midi kit 245 (Qiagen) and $1 \mu \mathrm{g}$ of RNA was reversed transcribed using random 246 hexamers (Applied Biosystems). Quantitative real-time PCR was 247 performed with the ABI Prism 7900 Sequence Detection System 248 (Applied Biosystems) using $5 \mu$ of 1:20 diluted cDNA in a final 249 volume of $25 \mu \mathrm{l}$ according to the manufacturer's recommenda- 250 tions. The reference and sequence of PCR primers and probes were 251 designed by Applied Biosystems (see Supplementary Material) 252 and used according to the manufacturer's recommendations. The 253 amount of sample RNA was normalized by amplification of an 254 endogenous control (18S). In each experiment, the relative 255 quantification of the transcripts was derived using the standard 256 curve method. Results obtained in the IGR-CaP1 cells were 257 compared to that found in LNCaP cells. 


\section{Immunohistochemistry (IHC)}

The different tissue specimens (primary tumors and potentially metastatic organs) from mice were fixed in Finefix (Milestone Medical), and then paraffin sections ( $4 \mu$ thick) were processed and stained with hematoxylin-eosin-saffranin (HES). Tumor and organ sections were incubated with anti-pan-CK (AE1/AE3/PCK26 (APK), Ventana Medical Systems), anti-p53 (Ventana Medical Systems), anti-PSMA (3E6) or anti-PAP (PASE/4LJ) from Diagnostic BioSystems, anti-Ki67 (Zymed), anti-CK14 (LL001, R\&D Systems) antibodies. All sections were analyzed using a Zeiss Axiophot microscope and a SensiCam PCO digital camera. Representative views were taken at $100 \times$ magnification.

\section{Immunofluorescence microscopy}

Cells were fixed in $4 \%$ formaldehyde, washed and then incubated with goat serum solution (1:100) and anti-human $\alpha 2 \beta 1$-integrin antibody (BHA2.1, Chemicon) followed by incubation with AlexaFluor 488 antibody (Molecular Probes). Nuclei were stained with Dapi vectashield mounting reagent (Vector Laboratories). Images were acquired on a Zeiss Axioplan 2 microscope.

\section{Spheroid soft agar assay}

Prostate spheroid cultures were made from IGR-CaP1 cells (P30). Cells were seeded at 10000 cells/well in 12 -well plates in $0.35 \%$ agarose in growth medium overlaid on a base of $0.8 \%$ agarose. Cultures were fed every 4-5 days for 2 weeks until colonies were formed. The 3D cultures were performed in classic RPMI medium supplemented with FBS. Cells grown as nonadherent spherical clusters were fixed in Finefix (Milestone Medical), collected using the cytoblock kit (Thermo laboratories) and embedded in paraffin. Then paraffin sections ( $4 \mu$ thick) were processed and stained with HES.

\section{Results}

\section{The IGR-CaP1 cell line is a prostate cancer epithelial cell line}

In a combination of ECM of human epithelial origin, IGR-XC and medium-which avoids fibroblast overgrowth-primary tumor fragments from three patients with localized disease were seeded and only one tumor fragment, from a 58-year-old prostate cancer patient, generated stabilized tumor cells after 20 subcultures in vitro. These cells were spontaneously immortalized since they were able to grow on plastic dishes in classic culture medium while retaining their proliferative capacity in a continuous long-term culture (up to 50 passages). They grew as adherent cells with epithelial cell morphology (Fig. 1A) and expressed the epithelial cell adhesion molecule EpCAM (Fig. 1B) as compared with the isotypic control or EpCAM-negative human fibroblasts IMR90 (not shown). They also stained positively for cytokeratin, as observed in the original tumor (Fig. 1C-D), confirming the epithelial origin of this cell line. The absence of chromogranin A expression in IGR-CaP1 cells led us to rule out the hypothesis of neuroendocrine cells while the lack of the mesenchymal markers STRO-1, CD73 and CD105 (not shown) and proline-depleted medium used to establish the cell line rather suggested that these cells did not correspond to mesenchymal cells either.
To better characterize the cell line, genotyping of the complete 311 Short Tandem Repeat (STR) profile was performed on total DNA 312 from the IGR-CaP1 cell line (Table 1). This technique allowed 313 definitive cell line authentication. The profiles confirmed the 314 complexity of the karyotype (Fig. 2A) and showed the absence of 315 the $\mathrm{Y}$ chromosome on the amelogenin locus. We observed the 316 same STR profile between DNA prepared from IGR-CaP1 cells at 317 passages 10 and 50, showing that chromosome alterations were 318 conserved throughout cultures. Since establishing a primary cell 319 culture may generate cellular heterogeneity, we undertook clonal 320 selection from the parental IGR-CaP1 cells by limit dilutions and 321 obtained nine clonally-derived clones. To definitively identify two 322 of them, named 3A11 and 3C11, the STR profile was determined 323 and showed some minor differences compared with that of the 324 parental IGR-CaP1 cell line (Table 1). Allelic changes were 325 observed at two loci vWA and D18S51, for the 3A11 derived 326 clone and at 5 loci D2S1338, D19S433, D18S51, D5S818 and FGA 327 for the 3C11 derived clone.

328

Karyotypic analysis was performed on the IGR-CaP1 cell line at 329 passage 29 using a conventional R-banding technique. The analysis 330 showed a complex tetraploid karyotype with 86-91 chromosomes, 331 including numerical and structural rearrangements (Fig. 2A). The 332 karyotype was determined to be $86 \sim 89<4 \mathrm{n}>$, XX, $+\operatorname{der}(\mathrm{X})$, + der 333 (X),-Y,-Y, der(1)t(1;?)(p32;?), add(2)(q3?2), -3,der(3)t(3;?) 334 (p10;?), -4, -4, -5, -5, -6, -6,ins(7;?)(p15;?),+8,+8,+11, 335 $+11,-13,-13, \operatorname{add}(13)(\mathrm{q} 31),-14,-15,-15, \operatorname{del}(18)(\mathrm{q} 22)$,del 336 $(18(q 22),+20, \operatorname{del}(20)(q 12),+\operatorname{del}(20)(q 12),+$ mar inc[cp15].

\section{IGR-CaP1 cells spontaneously express high telomerase 338} activity and show malignant features in vitro

Telomerase, the enzyme responsible for replicating telomeres, is 340 expressed at a low level in most normal tissues and becomes 341 activated during tumorigenesis. As telomerase expression can 342 itself induce immortalization [24], we measured the telomerase 343 activity in IGR-CaP1 cell extracts using a quantitative PCR system 344 targeting telomere extension products. The spontaneously im- 345 mortalized IGR-CaP1 cells exhibited high telomerase activity 346 compared with normal lymphocytes (PBL) (Fig. 2B). However, 347 this activity was lower than that measured in the PC3 cells derived 348 from a metastatic site.

Since mutations in the tumor suppressor gene Tp53 are 350 frequently associated with chromosome instability, Tp53 expres- 351 sion was examined in IGR-CaP1 cells. Immunohistochemical 352 analysis showed high Tp53 protein expression in the parental 353 tumor and in the derived cells (Fig. 2C-D). Tp53 expression in the 354 IGR-CaP1 cells (P16) was confirmed by Western Blot analysis with 355 the anti-Tp53 DO-7 antibody (not shown). High Tp53 expression 356 was assumed to correspond to the stabilized mutated Tp53 gene 357 product. Sequencing did indeed reveal a missense mutation at the 358 nucleotide A377G corresponding to a change at codon Y126C.

\section{Cell growth and kinetics}

The IGR-CaP1 cells grew rapidly in classic culture medium 361 conditions with a doubling time of $43 \mathrm{~h}$. Similar cell kinetics 362 were observed in medium containing charcoal-stripped FBS 363 (Fig. 3A). Treatment with DHT had no effect on IGR-CaP1 cell nor 364 
A

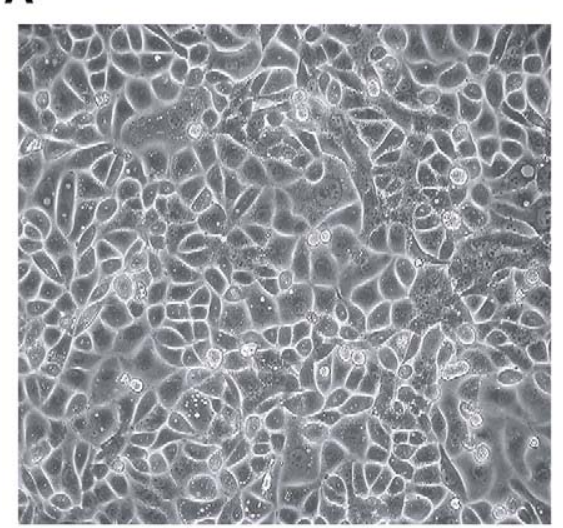

C

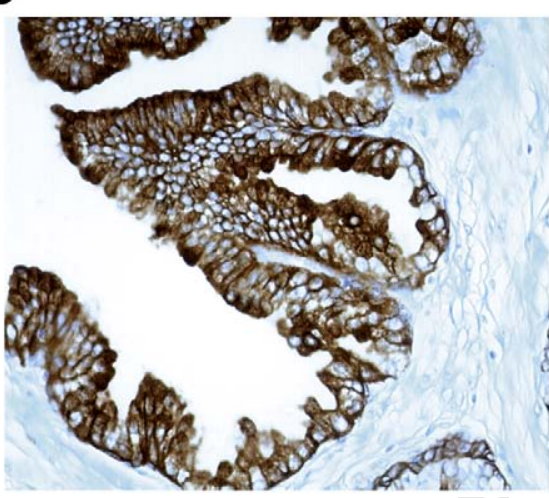

B

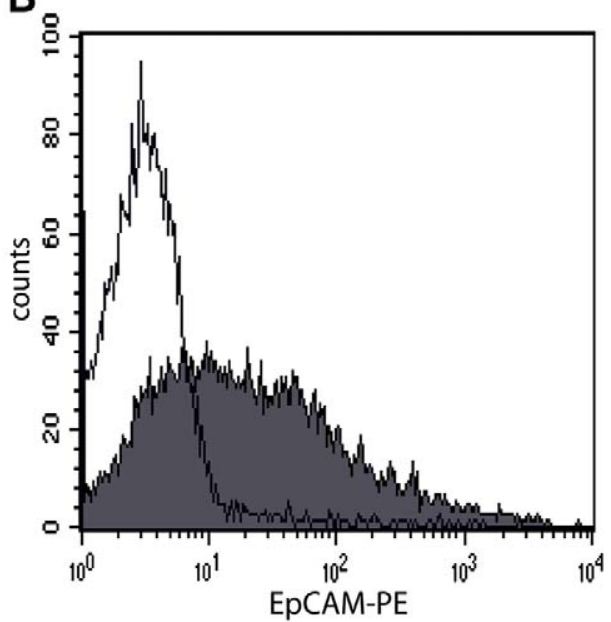

D

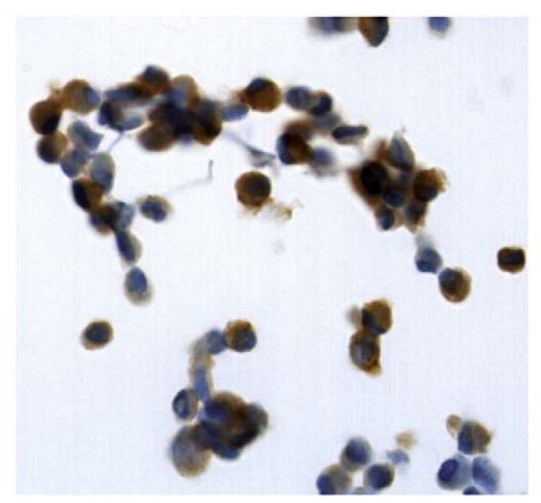

Fig. 1 - Morphology and epithelial features of the IGR-CaP1 cell line. (A) Photomicrograph of the human primary PCa cell line IGR-CaP1 (passage 29) shows typical epithelial morphology. (B) Expression of EpCAM was evaluated by FACS. (C-D) Cytokeratin expression was analyzed by IHC with anti-pan cytokeratin antibody (APK) in the initial tumor (C) and in IGR-CaP1 cells at passage 16 (D).

Table 1 - STR analysis for identification of IGR-CaP1 cells and the two clonally-derived clones $3 A 11$ and 3C11.

\begin{tabular}{llll}
\multicolumn{1}{c}{ Locus ID } & \multicolumn{1}{c}{ IGR-CaP1 } & \multicolumn{1}{c}{ 3A11 clone } & \multicolumn{1}{c}{ 3C11 clone } \\
\hline D8S1179 & $13-14-15-16-17$ & $13-14-15-16-17$ & $13-14-15-16-17$ \\
D21S11 & $26-30.2$ & $26-30.2$ & $26-30.2$ \\
D7S820 & $9.1-10.1-11.2$ & $9.1-10.1-11.2$ & $9.1-10.1-11.2$ \\
CSF1PO & $11-14-16$ & $11-14-16$ & $11-14-16$ \\
D3S1358 & $14-15$ & $14-15$ & $14-15$ \\
TH01 & $7-8-9.3$ & $7-8-9.3$ & $7-8-9.3$ \\
D13S317 & $8-10$ & $8-10$ & $8-10$ \\
D16S539 & $11-12-13$ & $11-12-13$ & $11-12-13$ \\
D2S1338 & $17-24-25$ & $17-24-25$ & $17-23-24$ \\
D19S433 & $13-14$ & $13-14$ & $12-13-14$ \\
vWA & $16-20-21$ & $16--19-22$ & $16-20-21$ \\
TPOX & $8-10-11$ & $8-10-11$ & $8-10-11$ \\
D18S51 & $14-15-16$ & $15-16$ & $15-16$ \\
Amelogenin & X & $X$ & $X$ \\
D5S818 & $12-13$ & $12-13$ & $12-13-16.1$ \\
FGA & $20-21-25-26$ & $20-21-25-26$ & $20-21-24-26$ \\
\hline
\end{tabular}

Loci were analyzed using the multiplex-PCR-based Identifier amplification kit (Applied Biosystems), comprising 15 autosomal STR Loci and the sex-chromosome marker amelogenin. on androgen-independent PC3 cell growth (Fig. 3B). Growth of 365 LNCaP cells was increased through a daily treatment with $10^{-9} \mathrm{M} 366$ DHT for 3 days to serve as a control.

\section{IGR-CaP1 cells do not express AR or PSA but express other prostate-specific markers}

IGR-CaP1 cells did not express androgen receptor protein (AR) or 370 secretory prostate-specific antigen (PSA) as shown by blot 371 analyses (Fig. 3C). The LNCaP and MDA-PCa-2b cells which both 372 express these two prostate markers were used as positive controls 373 while the PC3 cells were used as a negative control. FACS analysis 374 confirmed the absence of PSA and AR in IGR-CaP1 cells, as 375 compared to LNCaP and PC3 cell lines (Supplementary Fig. 1A). 376 Furthermore, in IGR-CaP1 cells neither AR nor PSA were detected 377 at mRNA levels by quantitative RT-PCR analyses (Fig. 3D). AR 378 protein and PSA expression in the IGR-CaP1 cell line contrasted 379 with that observed in the original tumor. The absence of AR and 380 PSA expression in the early passages of the IGR-CaP1 cell line 381 (Supplementary Fig. 1B) suggests that cells expressing AR were 382 lost during the in vitro cell culture establishment. It is established 383 that in prostatic epithelium, AR protein and PSA expression is 384 restricted to luminal secretory prostate cells and is not observed in 385 


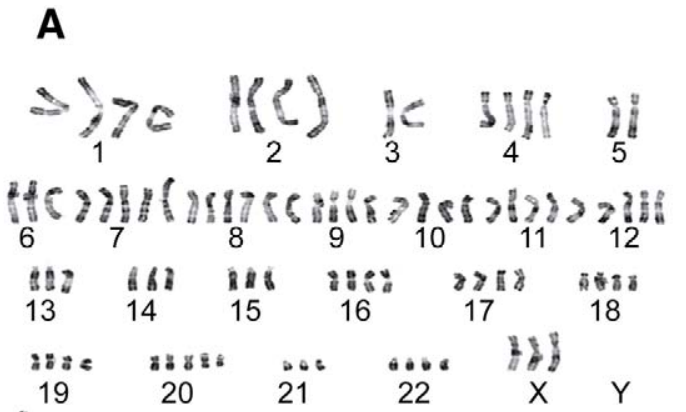

A

A

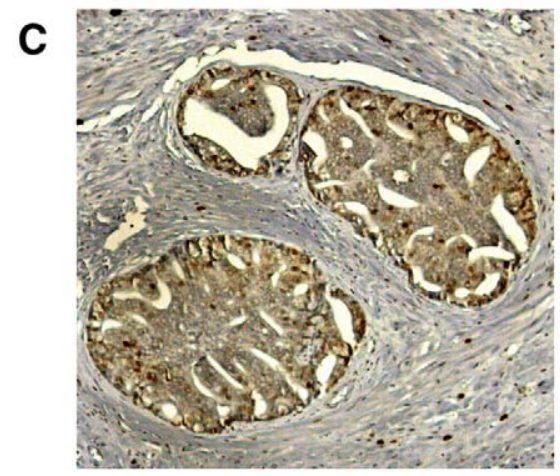

B
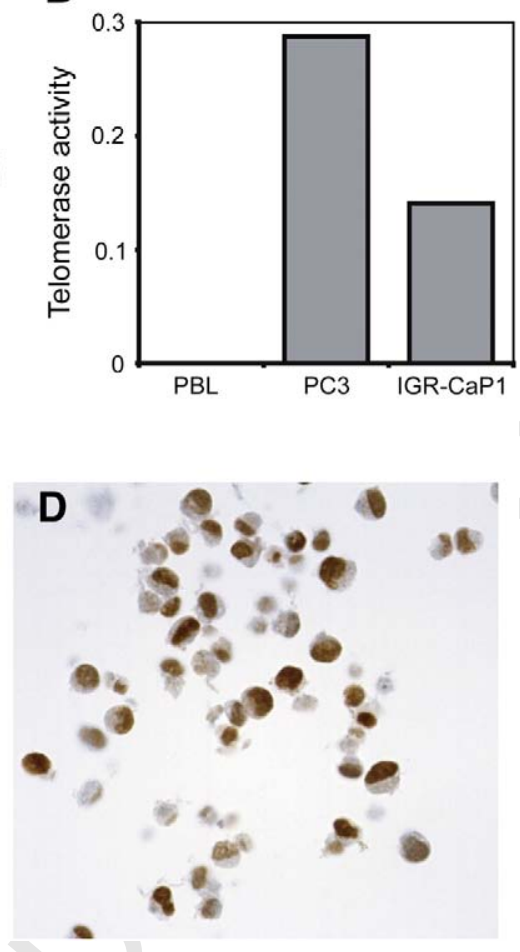

Fig. 2 - Malignancy features of the IGR-CaP1 cell line. (A) Karyotypic analysis of the IGR-CaP1 cell line using a conventional R-banding technique showing a complex tetraploid karyotype with 86-91 chromosomes. (B) Telomerase activity was quantified by quantitative PCR. Telomerase activity of IGR-CaP1 cells was compared to normal lymphocyte cells (PBL). PC3 cells were used as positive controls. (C-D) IHC showing high p53 expression in the initial prostatic tumor (C) and in the IGR-CaP1 cell line (D).

the basal layer cells of the epithelium, suggesting that IGR-CaP1 cells might correspond to basal epithelial prostate cancer cells.

Alpha-methylacyl-CoA-racemase (AMACR/ P504S) is a biomarker for prostate cancer that is strongly expressed in prostate cancer cell lines and tissues independently of androgen receptor expression $[25,26]$. As measured by FACS analysis, IGR-CaP1 cells expressed AMACR as also observed in LNCaP cells (Fig. 3E) and in PC3 cells (not shown). Like other prostate-specific markers, PSMA, the prostate-specific membrane antigen (also named FOLH1) [27] is expressed only in a small fraction $(\sim 2 \%)$ of IGR-CaP1 cells, as shown by flow cytometer analysis, compared to LNCaP cells (Fig. 3E). The low level of PSMA expression detected in in vitro culture conditions was in accordance with PSMA expression observed in orthotopic xenografts (Fig. 4B).

\section{IGR-CaP1 cells reconstitute prostate adenocarcinoma in mice}

To determine tumorigenicity of IGR-CaP1 cells in animals, cells were injected into male nude mice both subcutaneously and orthotopically. Subcutaneous injections of IGR-CaP1 cells resulted in the formation of palpable tumors within a week with $90 \%$ of mice (20/ 22) bearing tumors after 6-8 weeks (Fig. 4A). Orthotopic injection of IGR-CaP1 cells resulted in the formation of intraprostatic tumors (Fig. 4B). In all tumors, HES staining of sections revealed glandular differentiation with acini attesting the presence of adenocarcinoma. Immunohistochemical staining with Ki67 revealed a high proliferation index which was higher in the intraprostatic tumor than in subcutaneous xenografts, indicating more aggressive features in orthotopic tumors (Fig. 4A and B). All the neoplastic cells expressed cytokeratins, as shown with CK14 labelling (Fig. 4A), but none 413 expressed chromogranin A indicating an epithelial phenotype (not 414 shown). In addition, staining for both prostatic acid phosphatase 415 (PAP) and prostate-specific membrane antigen (PSMA) ascertained 416 the prostate origin of the tumor (Fig. 4A and B). Metastases were 417 observed in animals with both intraprostatic and subcutaneous 418 tumors and predominantly in the liver and lung (not shown). 419 Androgen responsiveness was then evaluated in vivo by castrating 420 animals $(n=5)$, once IGR-CaP1 tumors attained a volume of 421 approximately $300 \mathrm{~mm}^{3}$. Castration resulted in a slight reduction 422 of tumor progression although the difference was not statistically 423 different (interaction $p$-value $=0.096$ ) (Supplementary Fig. 2). This 424 suggests that although the androgen receptor was not expressed in 425 epithelial tumor cells, tumor progression was at least partially under 426 androgen control, thus emphasizing the importance of the tumor 427 microenvironment [28]. However, tumor progression in the castrat- 428 ed mice suggested that the epithelial tumor cells might possess 429 specific properties that were contributing to the survival of tumor 430 cells in response to androgen deprivation. Altogether, these data 431 showed that tumors initiated by the IGR-CaP1 cell line recapitulate 432 the characteristics of any initial human prostate cancer in mice. 433

\section{IGR-CaP1 cells express high levels of basal epithelial prostate 434 markers

To determine the phenotypes of IGR-CaP1 cells, we first examined 436 the expression of the cytokeratin markers CK5, CK8, CK14 and CK18 437 by cytometry analysis (Fig. 5A). The cytokeratin expression profile of 438 the luminal epithelial LNCaP cell line was used as a control. IGR-CaP1 439 
A

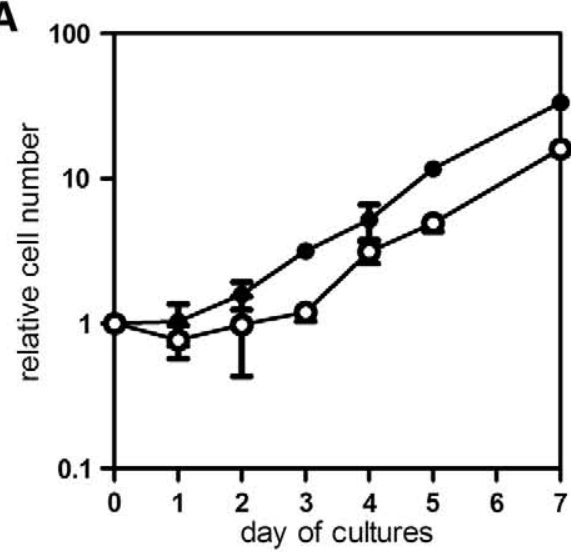

C

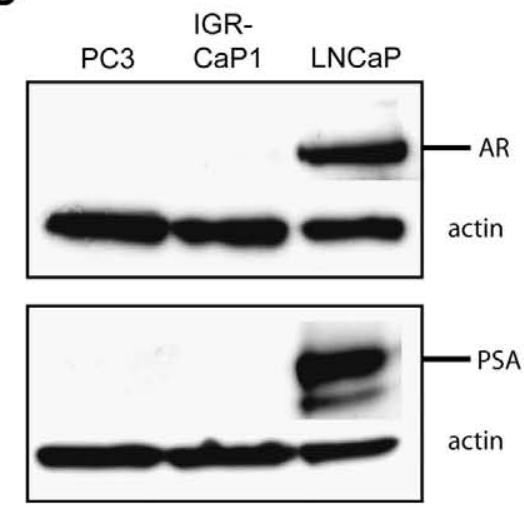

B

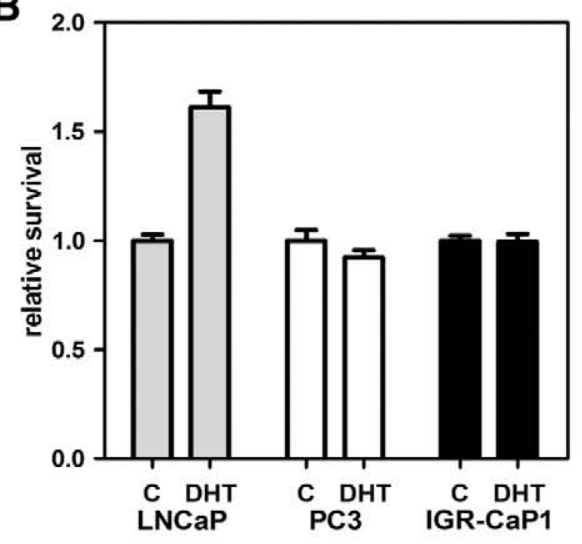

$\mathbf{E}$
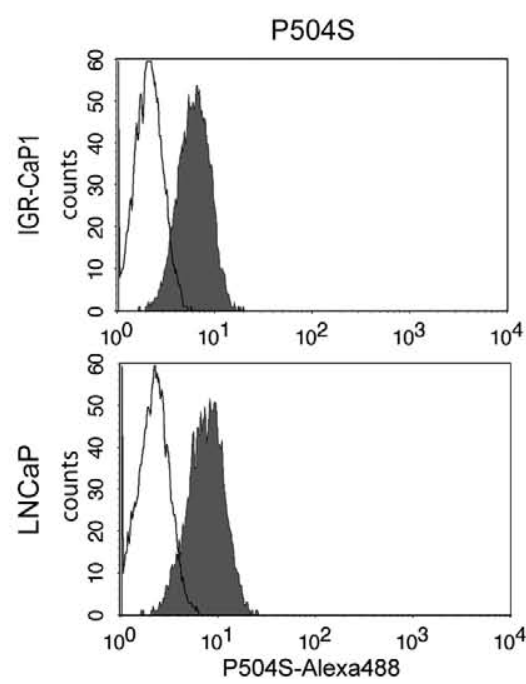

D
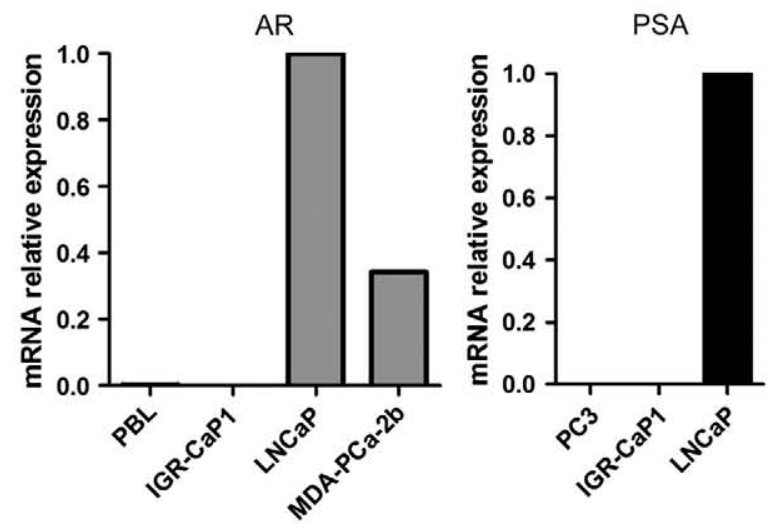

Fig. 3 - Cell growth, kinetics and expression of prostate-specific markers in IGR-CaP1 cells. (A) The growth rate of IGR-CaP1 cells at passage 28 was determined in culture medium supplemented with $10 \%$ FBS $(\bullet)$ or with $10 \%$ charcoal-stripped FBS $(O)$. (B) The survival of IGR-CaP1, LNCaP and PC3 cells was determined after treatment of $10^{-9} \mathrm{M}$ DHT for $72 \mathrm{~h}$ compared to no treatment (C) in medium supplemented with charcoal-stripped FBS. (C) Blot analysis showed no expression neither of AR nor of PSA in IGR-CaP1 cells compared to that found in PC3 and LNCaP cells respectively used as negative and positive controls. (D) The absence of AR and PSA gene expression was confirmed by quantitative RT-PCR analyses when compared with mRNA extracted from MDA-PCa-2b and from LNCaP cells as positive controls. (E) The expression level of the prostate markers P504S (AMACR) and PSMA was evaluated by flow cytometry. LNCaP cells were used as controls. 
A

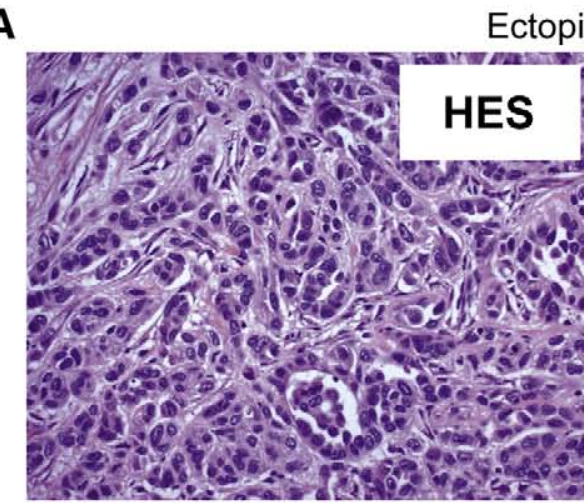

Ectopic tumor
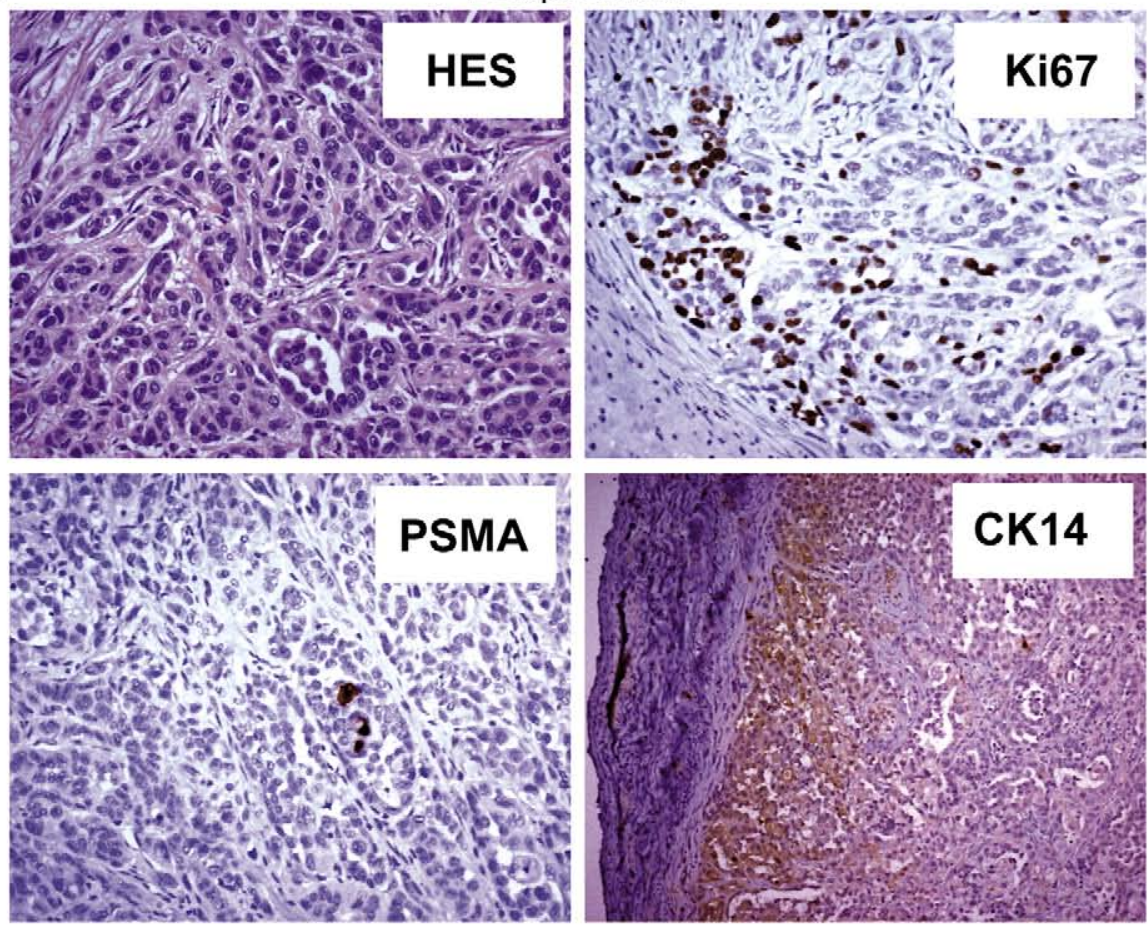

B

Intraprostatic tumor
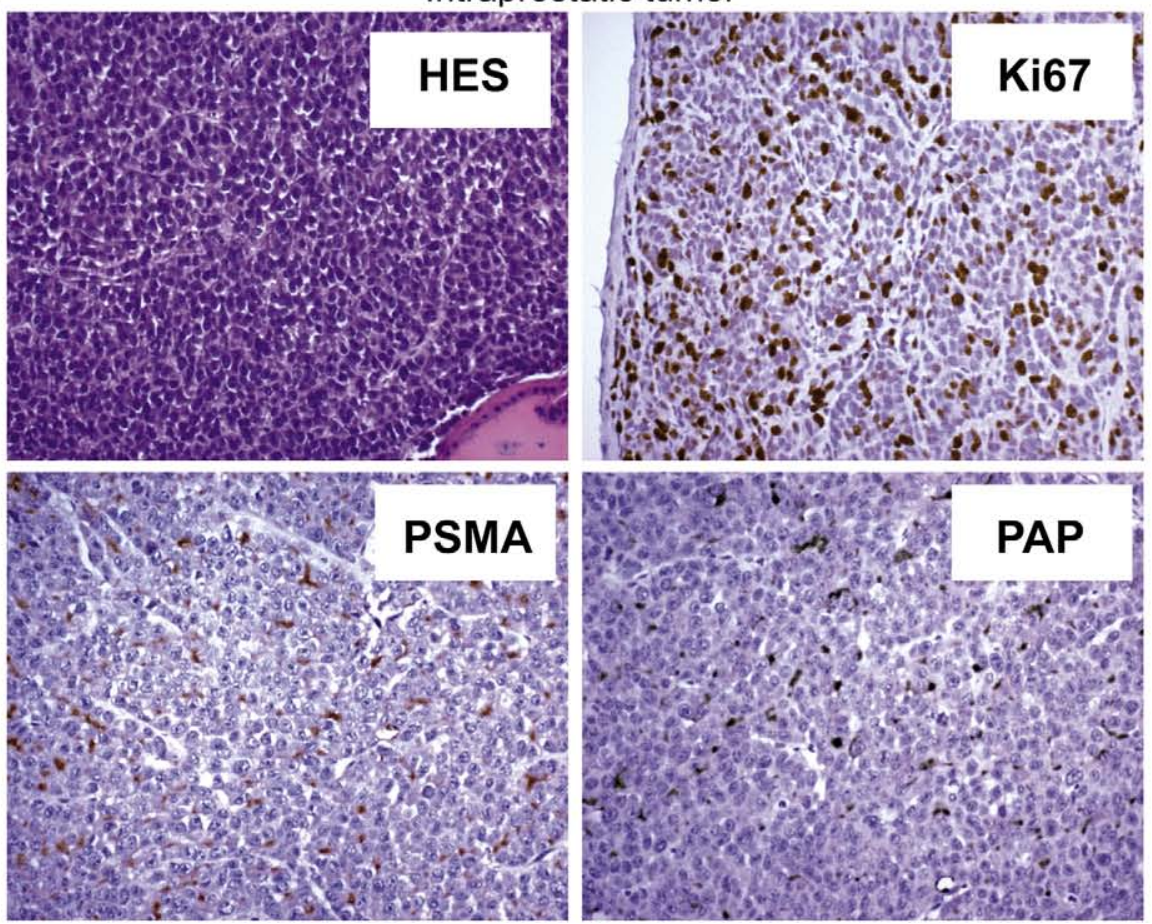

Fig. 4 - IGR-CaP1 cells reconstitute adenocarcinoma in mice. IGR-CaP1 cells were injected into male nude mice both subcutaneously (A) or intraprostatically (B). HES staining of tumor sections revealed glandular differentiation with acini confirming the presence of adenocarcinoma. CK14 attested the epithelial origin of the tumor. Ki67 staining revealed the proliferation index. Markers corresponding to prostatic acid phosphatase (PAP) and the prostate secreted membrane antigen (PSMA) confirmed the prostate origin of the tumor.

cells exhibited strong staining for CK5/8 and CK14 but no staining for CK8. Although adult prostate basal cells have been shown to express p63, we did not detect p63 expression in these cells (not shown). We detected low labelling for the luminal epithelial marker CK18 in IGR- 443 CaP1 cells compared to that observed in LNCaP cells (93\% CK18 444 fluorescence in LNCaP versus 34\% in IGR-CaP1 cells). The absence of 445 
CK8 and the low level of CK18 expression indicated the absence of luminal differentiation in cultured IGR-CaP1 cells. Additionally, CK19 expression was detected in early passages of the IGR-CaP1 cell line, but disappeared during in vitro passaging and was not detectable in cells at passage 71 (not shown). The two clones 3A11 and 3C11 exhibited roughly the same cytokeratin expression profile. These results as a whole indicate that the IGR-CaP1 cell line displays a cytokeratin profile corresponding to basal epithelial cells. As prostate stem cells have been shown to exist in the basal cell compartment, these data suggested that a small subset of these cells expressing a broad spectrum cytokeratin profile might correspond to progenitor/ stem cells.

\section{IGR-CaP1 cells and clonally-derived clones show features of prostate cancer stem cells}

Previous studies have suggested that putative prostate progenitor/ stem cells are located in the basal layer and express markers of basal cells. As in the normal prostate, the putative stem cell population was shown to be enriched in CD44 and CD133 antigens [11], we first evaluated their expression levels in the IGR-CaP1 cell line by flow cytometry (Fig. 5B). Compared to LNCaP cells in which only a minor fraction expressed CD44, almost all the IGR-CaP1 cells expressed CD44 antigen. CD133 expression was not observed in LNCaP cells. In contrast, we detected two populations in IGR-CaP1 cells, one exhibiting high CD133 expression and the other was CD133-negative. CXCR4, a key molecule in the regulation of the migratory and metastatic properties of cancer cells, may be essential for the progression of the $\mathrm{CD} 133^{+}$prostate cancer stem cells [15]. We found that a large subset of IGR-CaP1 cells expressed the CXCR4 molecule. In addition, we found that all the IGR-CaP1 cells were CD24 positive (Supplementary Fig. 3A). Real-time quantitative RT-PCR confirmed high expression of CD44 in the parental IGR-CaP1 cell line and in the clonally-derived clones 3A11 and 3 C11 (mean Ct of 25.8) whereas CD44 gene expression was not detectable in LNCaP cells $(\mathrm{Ct}>40)$ (not shown). High expression of CD133 and CXCR4 was also confirmed by RT-PCR performed at different passages (Fig. 5C). The combined biomarker expression after triple-labelling and flow cytometry analysis was evaluated and showed a high fraction of $\mathrm{CD} 44^{+} / \mathrm{CD} 133^{+} / \mathrm{CXCR}^{+}$ triple-labelled cells ( $13 \%$ of the population in the parental IGRCaP1 cells , 23\% and 34\% in 3A11 and 3C11 clones respectively) (Supplementary Fig. 3B). Furthermore, as it has been postulated that anchorage-independent culture of tumor cells is a useful tool for enriching and characterizing stem cells, we next investigated the clonogenic capacity in a soft agar assay. The results showed that IGR-CaP1 cells were able to form spheroids $(\sim 200 \mu \mathrm{m})$ in serum-supplemented RPMI medium and HES staining showed glandular-like structures with a lumen (Fig. 5D). These findings suggest that IGR-CaP1 cells possess stem cell-like characteristics. We next investigated the ability of IGR-CaP1 cells to maintain their characteristics after xenografting into animals. Cells were xenografted subcutaneously into nude mice. Subsequently, after 2 months of tumor growth, tumor cells were dissociated by enzymatic digestion and plated in culture dishes in classic culture conditions. After 5 passages of in vitro culture, stem cell markers and basal epithelial markers were assessed by FACS analysis. The results in Fig. 5E show that even after xenografting into mice and solid tumor growth, the IGR-CaP1 cells retained the characteristics of prostate basal epithelial cells (CK5 and CK14) and the potential of CSC (CD44, CD133 and CXCR4). In particular, we still observed 504 the same fraction of CD133 positive cells ( $~ 50 \%$ of the cells). 505 Interestingly, CXCR4 expression was increased in these conditions 506 (75\% of CXCR4 positive cells). The small fraction of PSMA positive 507 cells was also conserved. Thus, these results strengthened the 508 value of the IGR-CaP1 model as a model system based on tumor 509 stem cells originating from the basal epithelium.

\section{IGR-CaP1 cells show a stem cell expression signature}

As the $\alpha 2 \beta 1^{\mathrm{hi}} / \mathrm{CD} 133^{+}$phenotype is the hallmark of normal 512 prostate epithelial stem cells [11], $\alpha 2 \beta 1$-integrin staining of IGR- 513 CaP1 and clonally-derived clones was performed (Fig. 6A). High 514 expression of these phenotypic markers in the IGR-CaP1 cells and 515 the two clones 3A11 and 3C11, suggested the occurrence of a large 516 subset of cells exhibiting the characteristics of stem cells, and 517 possibly corresponding to stem cells.

We then explored whether other signalling pathways involved in 519 stemness could be activated in IGR-CaP1 cells. We investigated Oct4 520 which was previously reported to be expressed in pluripotent 521 embryonic stem (ES) cells and in hTERT-immortalized HPE (HPET) 522 cells $[14,29]$. Microarray analysis performed on IGR-CaP1 cells 523 revealed Oct4 gene expression. By using an antibody that exclusively 524 recognizes the Oct-4 (OCT4A) isoform-1, Western Blot analysis 525 confirmed Oct4 expression in IGR-CaP1 cells, unlike that found in 526 LNCaP and PC3 cells used as controls (Fig. 6B). Since the Hedgehog 527 (HH) signalling pathway regulates key functions of stem/progenitor 528 cell self-renewal [30,31], we used real-time RT-PCR to assess its 529 expression in IGR-CaP1 cells compared to the LNCaP cell line. The 530 SHH gene was highly expressed in IGR-CaP1 cells with concomitant 531 expression of GLI1 and GLI2 target gene products. The HH receptor 532 Patched protein $\mathrm{PTCH}$, which normally blocks the pathway, was 533 slightly downregulated in IGR-CaP1 cells (Fig. 6C). Similar results 534 were obtained in the two clones 3A11 and 3C11, except for the GLI2 535 gene which exhibited higher expression in the 3A11 clone and lower 536 expression in the $3 \mathrm{C} 11$ clone.

We then assessed the expression of two other proteins which 538 have been implicated in stem-like cell populations. We observed 4- 539 fold higher expression of NOTCH1 gene in IGR-CaP1 cells compared to 540 LNCaP cells, consistent with previous results showing that Notch gene 541 expression was restricted to basal epithelial cells [32]. In agreement 542 with detection of the breast cancer resistance protein BCRP/ABCG2 in 543 basal epithelial CD133+ prostate cells [33], IGR-CaP1 cells also 544 expressed a high level of mRNA coding for ABCG2 gene (Fig. 6D). 545 Similar results were obtained in the two clones 3A11 and 3C11.

Herein, we describe the establishment and characterization of a new 549 prostate cancer cell line named IGR-CaP1 obtained from a primary 550 prostate cancer. Although cell lines from primary prostate carcino- 551 mas are among the most difficult to establish in vitro, we took 552 advantage of the natural extracellular matrix (IGR-XC) we recently 553 developed and already used successfully to obtain cell lines derived 554 from human carcinomas of unknown primary [34], to obtain a new 555 cell line derived from a patient with a clinically localized prostate 556 cancer. The IGR-CaP1 cell line was cultured up to passage 50. Nine 557 clones were derived by limiting dilution cloning and two of them, 558 
A
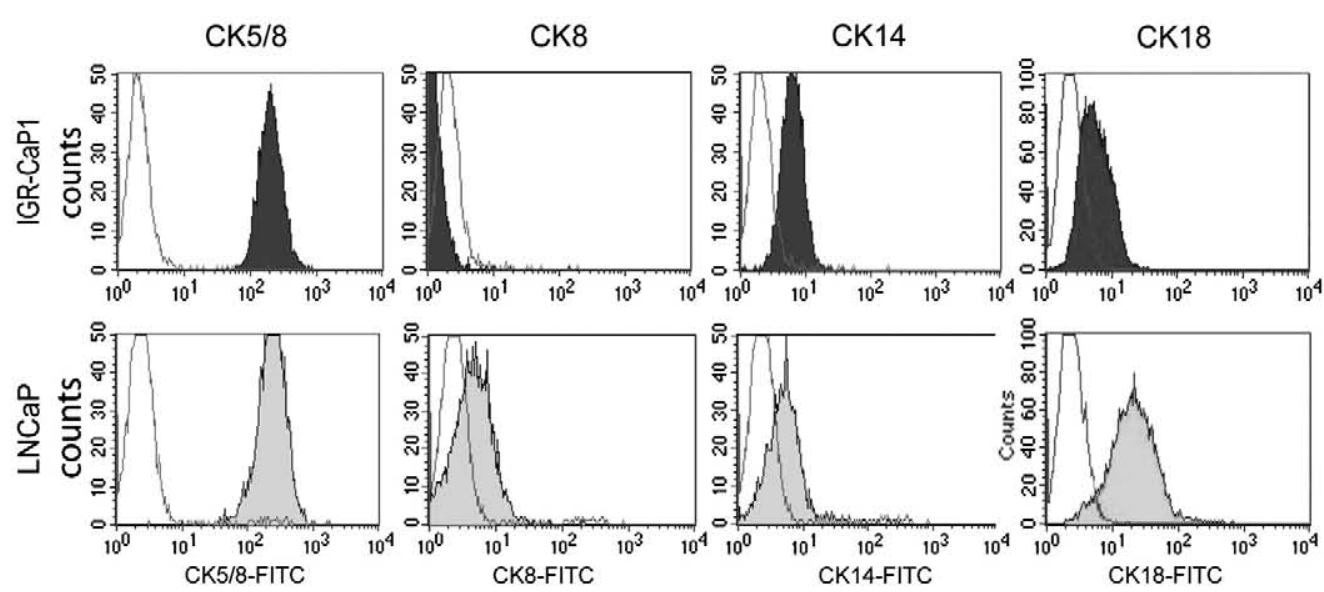

B
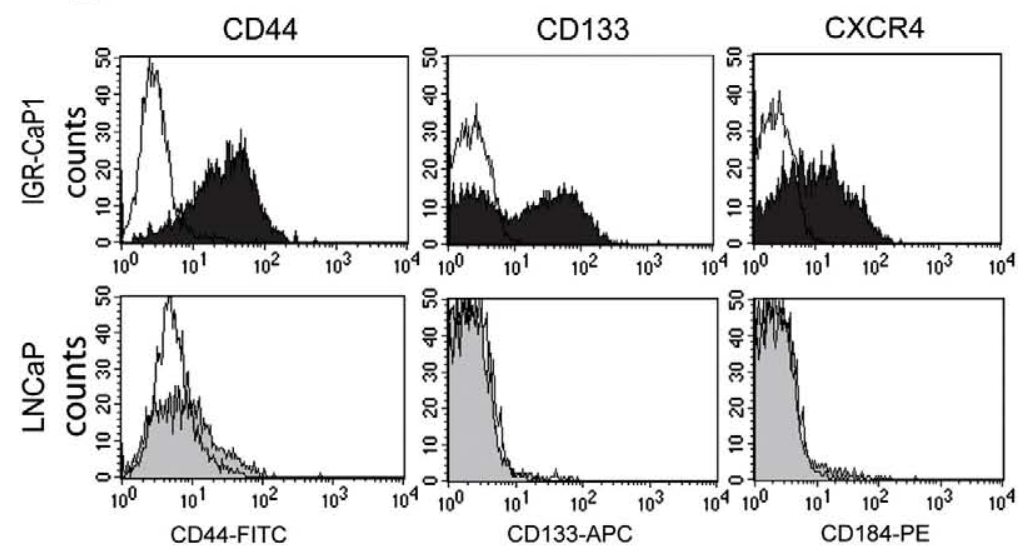

C
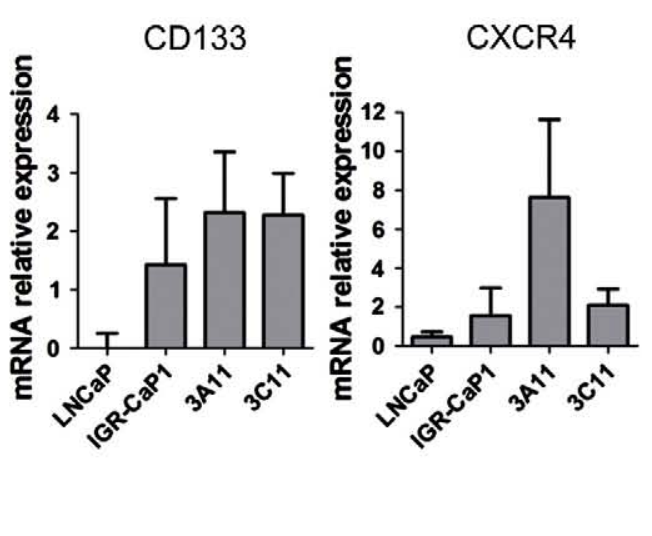

D
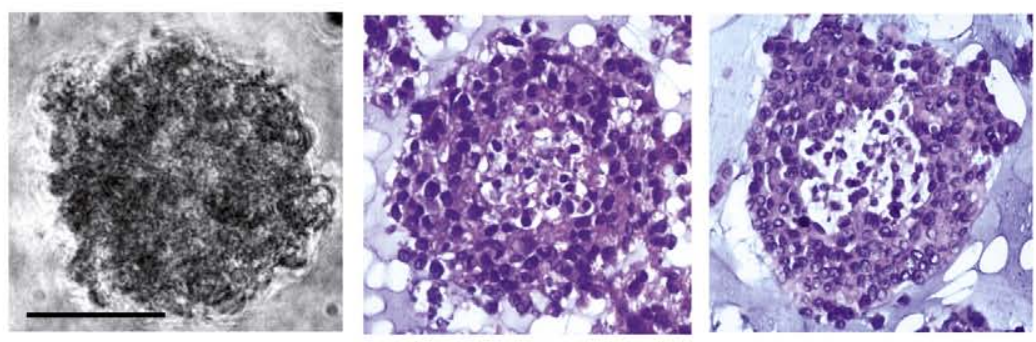

E
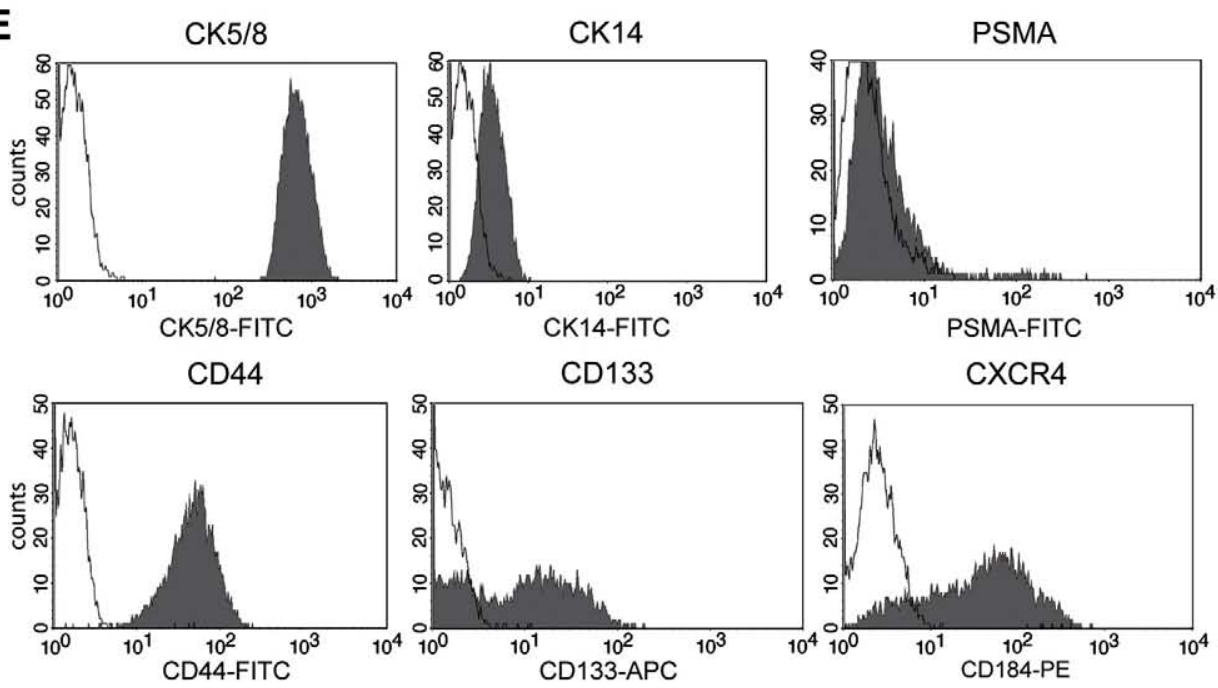

Please cite this article as: A. Chauchereau, et al., Stemness markers characterize IGR-CaP1, a new cell line derived from primary epithelial prostate cancer, Exp. Cell. Res. (2010), doi:10.1016/j.yexcr.2010.10.012 
3A11 and 3C11, were cultured up to passage 10. The complete identification of the new IGR-CaP1 cell line was achieved using STR profiling (Table 1 ).

The chromosome abnormalities confirmed malignancy in IGRCaP1 cells which exhibited a tetraploid karyotype. Given the lack of prostate cancer models, telomerase-immortalized human prostate epithelial (HPET) cells provide useful models since they display prostate stem cell properties and also reconstitute the original prostate cancer specimen [14,15,31]. We showed that IGR-CaP1 cells spontaneously elicit high telomerase activity thus attesting the malignant potential of these cells. Undoubtedly, the endogenously hTERT-expressing IGR-CaP1 cells are more relevant to investigate the early steps of prostate oncogenesis because the key regulatory steps involved in telomerase activation in tumorigenesis may be missed in HPET cells. Somatic Tp53 mutations in primary tumors are associated with prostate cancer progression and a propensity for metastasis $[35,36]$. In this respect, the missense mutation identified in the IGR-CaP1 cell line at position 126 of the Tp53 correlates with the high Tp53 protein expression found in both of these in vitro propagated cells and in the original tumor. It is possible that both properties, tetraploidy and mutated Tp53 expression, played a role in the establishment of the IGR-CaP1 cell line. Indeed, reports supported that tetraploid cells occur as an early step in tumor formation thus, conferring a survival advantage on tumor cells during the in vitro process [37]. Tetraploidy might have been maintained due to the presence of a mutated Tp53. Indeed, it has been shown that a "tetraploid checkpoint" is normally controlled by wild-type Tp53 to avoid the proliferation of tetraploid cells [38].

Interestingly, and consistent with the results obtained in vitro, the successful engraftment of IGR-CaP1 in nude mice plus their ability to metastasize to the liver and lung, enable us to propose IGR-CaP1 as an invaluable experimental model of PCa. Strikingly, preliminary data obtained 10 weeks after intra-tibia injections of the IGR-CaP1 cells into nude mice, imaged by high-resolution microCT scan, showed both osteoblastic and osteolysis lesions suggesting that these cells induced bone remodelling, as regularly observed in patient bone metastases (Supplementary Fig. 4).

IGR-CaP1 cells do not express AR nor the androgen-regulated gene PSA unlike the original tumor, suggesting a selective survival advantage of AR-negative cells and the loss of differentiated ARpositive cells during the early steps of in vitro tumor culture. Consistent with the lack of AR and PSA expression, the IGR-CaP1 cells express the basal epithelial cytokeratins, CK5 and CK14 and did not express the luminal CK8 markers. This is in full agreement with the working hypothesis of the occurrence of a small population of epithelial stem cells in the basal cell layer, giving rise to basal cells and intermediate transit-amplifying cells [31]. As we also detected CK18 expression, albeit at a much lower level, this strongly suggests that IGR-CaP1 cells mainly correspond to 607 basal epithelial cells and that CK18 expression may be attributed to 608 the existence of some intermediate transit-amplifying cells. $\quad 609$

Considerable efforts are currently being expended to identify 610 cells at the origin of prostate cancer. A growing body of literature 611 supports that cancer lethality results from the hierarchical expansion 612 of "cancer-initiating cells" or "cancer stem cells" (CSC), which 613 function as stem-like cells to maintain malignant growth [39]. 614 Several potential markers of CSCs have been used to identify putative 615 CSCs in several solid cancers and can potentially be used to isolate 616 and characterize CSCs. One of the major reported CSC markers is 617 CD133 which is a marker for both human normal prostate stem cells 618 and prostate CSC [11]. Other studies showed that putative prostatic 619 stem cells with the $\alpha 2 \beta 1^{\mathrm{hi}} / \mathrm{CD} 44^{+} / \mathrm{CD} 133^{+}$phenotype were able to 620 reconstitute prostate-like acini in mice that expressed differentiated 621 cell markers [12]. More recently, co-expression of CXCR4 was 622 demonstrated in $\mathrm{CD}_{133^{+}}$human prostatic epithelial cells immor- 623 talized with hTERT [15]. We showed that IGR-CaP1 cells exhibit high 624 expression of cancer stem cell CD44, CD133 markers and CXCR4, and 625 exhibit notably a high proportion (47\%) of CD133-expressing cells 626 thus clearly identifying two populations of CD133-positive and 627 CD133-negative cells. Two sub-populations were also observed 628 based on the wide difference in $\alpha 2 \beta 1$-integrin labelling. Therefore, 629 as multiple populations with CSC characteristics may co-exist either 630 in the same cell line or in the same tumor, this strongly suggests that 631 our cell line corresponds to CSC-derived cancer progenitor cells 632 capable of giving rise to clonal expansion. Such an assessment is fully 633 consistent with the conclusions of Campbell and Polyak, as well as 634 Adams and Strasser $[40,41]$ suggesting that although CSCs are a 635 special subset of tumor cells, they still constitute a heterogeneous 636 population with different biological properties.

There are several other signalling pathways including the $\mathrm{HH}$ and 638 NOTCH pathways that are so far reported to be involved in the 639 maintenance of stem or progenitor cells of many adult tissues, and 640 also shown to operate in human PCa progression [42-48]. As a 641 matter of fact, Sonic Hedgehog pathway (HH-GLI) activation and 642 high expression of the NOTCH-1 gene suggest that this signalling 643 pathway could be involved in the maintenance of the "CSC-like" 644 population within the IGR-CaP1 cells. Oct-4 expression which was 645 reported in HPET cells [14,16] and seems to play a crucial role in 646 resistance to chemotherapy in lung cancer CD133+ cells [49], is also 647 detected in IGR-CaP1 cells. It is noteworthy that high expression of 648 the BCRP/ABCG2 gene provides an additional stem cell marker in the 649 IGR-CaP1 cells. Taken together, this further suggests that the self- 650 renewal genes including $\mathrm{HH}$, Notch-1, Oct4 and ABCG2, may be 651 implicated in the self-renewal properties of IGR-CaP1 cells. 652

In conclusion, the IGR-CaP1 cell line is a new model of prostate 653 cancer derived from a primary tumor exhibiting high tumorigenic 654

Fig. 5 - Basal-type cytokeratin profile and cancer stem cell marker expression. (A) Cytokeratin marker expression was measured in IGR-CaP1 cells by FACS. LNCaP cells were used as controls. (B) The expression level of the stem cell markers CD44, CD133 and CXCR4 (also named CD184) was evaluated by flow cytometry. LNCaP cells were used as controls. (C) CD133 and CXCR4 gene expression levels were measured by QRT-PCR in IGR-CaP1 cells and in the clones 3A11 and 3C11 using a range of passages for the IGR-CaP1 cells (P26, P31, P48 and P64), P7, P8 and P10 for the 3A11 clone and P6, P7 and P9 for the 3C11 clone. Two different samples were used for the control LNCaP cell line. Results are expressed as means \pm SD and compared to the LNCaP cells as the reference. (D) Anchorageindependent growth of IGR-CaP1 cells in soft-agar assay showing spheroids grown in RPMI medium. Representative HES-stained section. Scale-bar: $100 \mu \mathrm{m}$ (E) Re-establishment of the IGR-CaP1 cell line after xenografting into nude mice. Basal cytokeratin profiles, stem cell markers and PSMA expression after engraftment in animals and re-establishment in vitro of IGR-CaP1 cells (P5). Results are representative of what was obtained in the 4 newly established cells after mouse engraftment. 


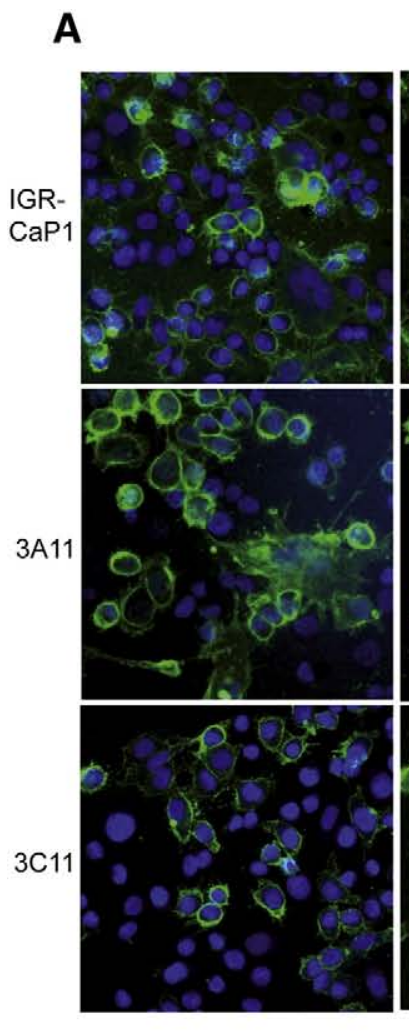

$\alpha 2 \beta 1$ integrin
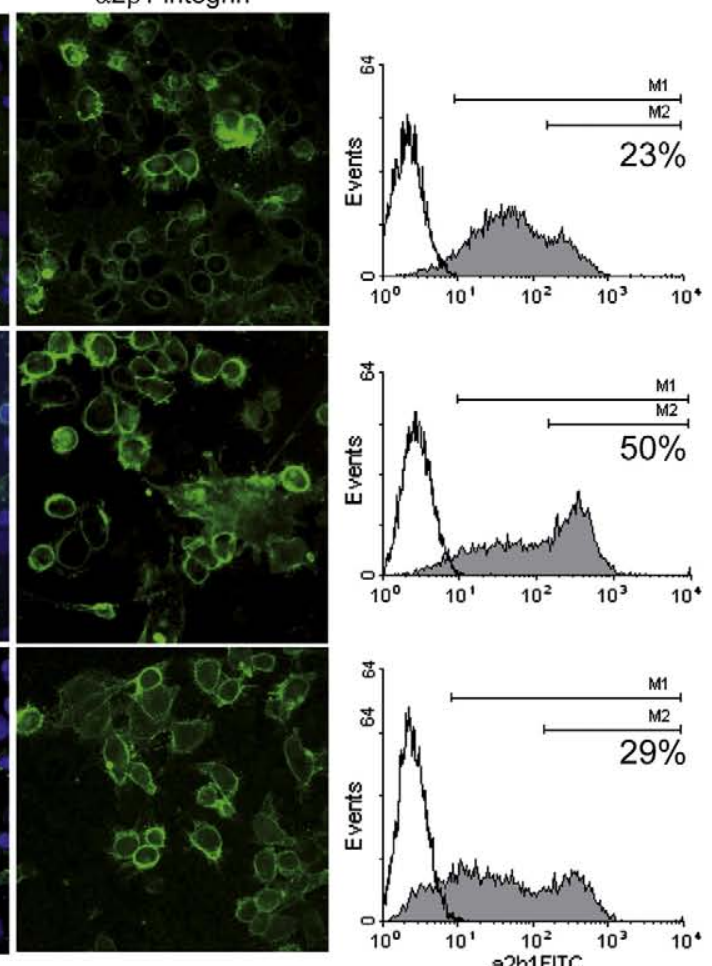

B
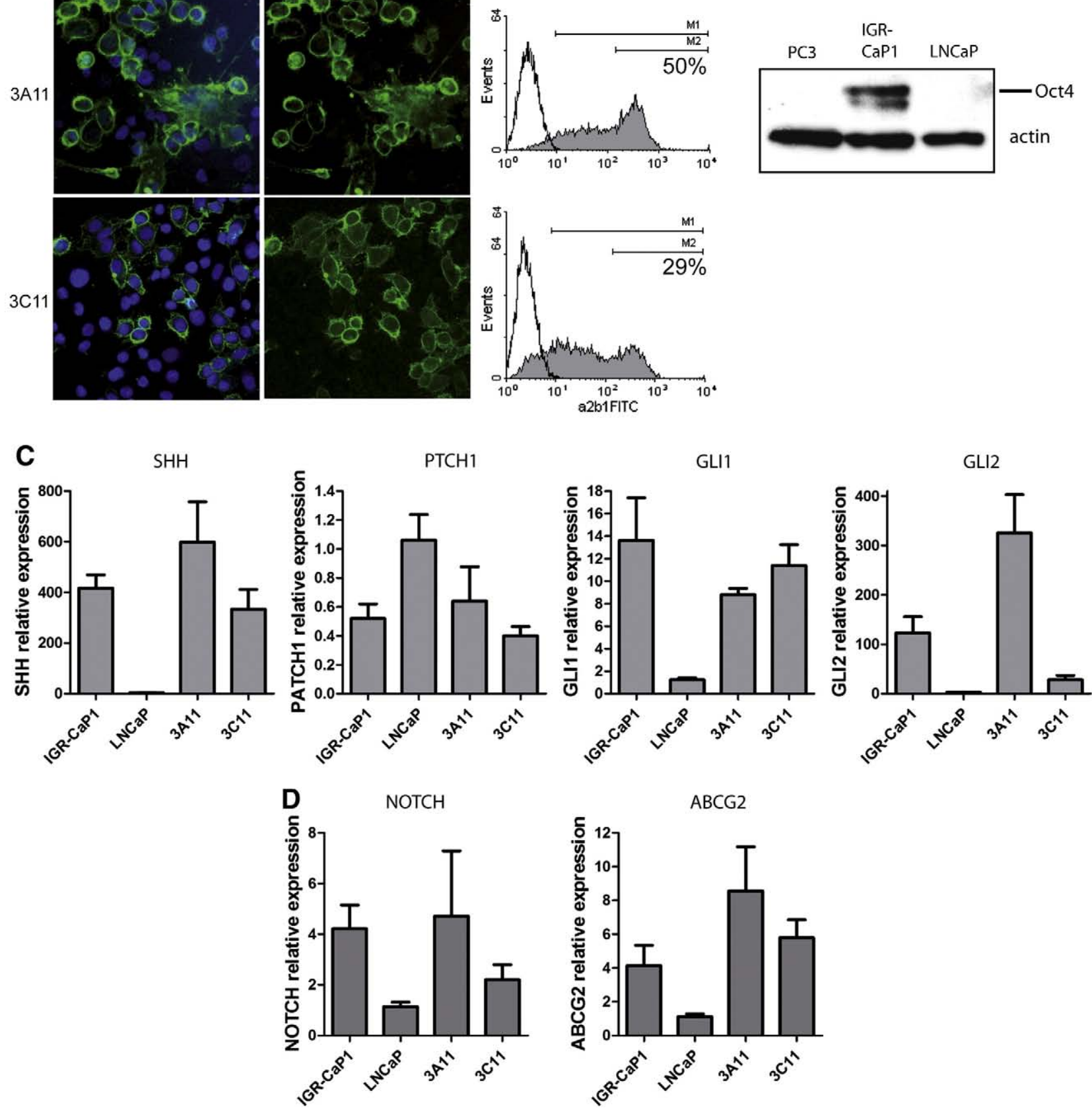

Fig. 6 - Stem cell signalling pathways in IGR-CaP1 cells. (A) $\alpha 2 \beta 1$-integrin was measured by immunofluorescence and by FACS in IGR-CaP1 cells and in the 3A11 and 3C11 clones, using anti-VLA-2 antibody. The nuclei were counterstained with Dapi. The fraction of $\alpha 2 \beta 1$ integrin $^{\text {high }}$-expressing cells was estimated with the M2 marker (B) Oct4 expression was evaluated by blot analysis in IGRCaP1 cell extracts and compared with that found in PC3 and LNCaP cells. (C and D) QRT-PCR was used to determine the expression level of markers identified as regulators of normal prostate stem/progenitor cells. Multiple passage levels were used as in Fig. 5C. Results are expressed as means \pm SEM and compared to the LNCaP cells used as controls. 
properties in vivo. Spontaneously immortalized, these mutated Tp53 tetraploid cells express hTERT and high-level expression of stem cell markers (CD44, CD133, $\alpha 2 \beta 1$-integrin). Additionally, the IGR-CaP1 cells possess additional CSC characteristics, namely a 3D sphere-forming ability and a renewal capacity by maintaining their CSC potential after xenografting into mice. Thus, the IGRCaP1 cell line derived from a primary tumor represents an experimental model of an aggressive prostate tumor with stem cell properties. Moreover, the stem cell signature provides an invaluable tool for investigating the mechanisms of resistance to chemotherapy and radiation. It could be used to study new therapeutic strategies both in vitro and in vivo, namely new therapeutic strategies targeting the stem cell properties of cancer cells.

Supplementary materials related to this article can be found online at doi:10.1016/j.yexcr.2010.10.012.

\section{Disclosure statement}

This new IGR-CaP1 cell line was the subject of a European patent pending entitled "Prostate cancer cell lines and their use in screening method" deposed on the April 14th, 2009. Biological material has been deposited at the Pasteur Institut (Paris) (CNCM I-4126). The patented material will be available under a Material Transfer Agreement for research use.

\section{Acknowledgments}

We would like to thank E. Connault and F. Tabarin for excellent technical assistance. We also thank gratefully F. Commo for his help in statistical analysis. N.A.N was supported by the Association pour la Recherche sur les Tumeurs de la Prostate (ARTP) and is supported by the Association pour la Recherche sur le Cancer (ARC). D.C. is supported by ARTP (France), by the Prostate Cancer Research Fundation (PCRF, UK) and SALES Fundation (Argentina). We also thank L. Saint-Ange for editing.

\section{REFERENCES}

[1] A.M. Lin, E.J. Small, Prostate cancer update: 2007, Curr. Opin. Oncol. 20 (2008) 294-299.

[2] K. Fizazi, N.M. Navone, Preclinical models of prostate cancer, Bull. Cancer 92 (2005) 129-141.

[3] R.E. Sobel, M.D. Sadar, Cell lines used in prostate cancer research: a compendium of old and new lines-part 2, J. Urol. 173 (2005) 360-372.

[4] S. Koochekpour, G.A. Maresh, A. Katner, K. Parker-Johnson, T.J. Lee, F.E. Hebert, Y.S. Kao, J. Skinner, W. Rayford, Establishment and characterization of a primary androgen-responsive African-American prostate cancer cell line, E006AA, Prostate 60 (2004) 141-152.

[5] S.R. Selvan, A.N. Cornforth, N.P. Rao, Y.A. Reid, P.M. Schiltz, R.P. Liao, D.T. Price, F.S. Heinemann, R.O. Dillman, Establishment and characterization of a human primary prostate carcinoma cell line, HH870, Prostate 63 (2005) 91-103.

[6] J.M. D'Antonio, D.J. Vander Griend, L. Antony, G. Ndikuyeze, S.L. Dalrymple, S. Koochekpour, J.T. Isaacs, Loss of androgen receptor-dependent growth suppression by prostate cancer cells $\quad 710$ can occur independently from acquiring oncogenic addiction to 711 androgen receptor signalling, PLoS ONE 5 (2010) e11475. 712

[7] G. Attard, S. Rizzo, I. Ledaki, J. Clark, A.H. Reid, A. Thompson, 713 V. Khoo, J.S. de Bono, C.S. Cooper, D.L. Hudson, A novel, 714 spontaneously immortalized, human prostate cancer cell line, $\quad 715$ Bob, offers a unique model for pre-clinical prostate cancer studies, 716 Prostate 69 (2009) 1507-1520.

[8] J.E. Visvader, G.J. Lindeman, Cancer stem cells in solid tumors: 718 $\begin{array}{ll}\text { accumulating evidence and unresolved questions, Nat. Rev. } & 719\end{array}$ Cancer 8 (2008) 755-768.

[9] R.A. Taylor, G.P. Risbridger, The path toward identifying prostatic 721 stem cells, Differentiation 76 (2008) 671-681.

[10] A.T. Collins, F.K. Habib, N.J. Maitland, D.E. Neal, Identification and 723 isolation of human prostate epithelial stem cells based on alpha 724 (2)beta(1)-integrin expression, J. Cell Sci. 114 (2001) 3865-3872. 725

[11] G.D. Richardson, C.N. Robson, S.H. Lang, D.E. Neal, N.J. Maitland, A. 726 T. Collins, CD133, a novel marker for human prostatic epithelial 727 stem cells, J. Cell Sci. 117 (2004) 3539-3545.

[12] A.T. Collins, P.A. Berry, C. Hyde, M.J. Stower, N.J. Maitland, Prospective identification of tumorigenic prostate cancer stem cells, Cancer Res. 65 (2005) 10946-10951.

[13] B. Daly-Burns, T.N. Alam, A. Mackay, J. Clark, C.J. Shepherd, S. Rizzo, R. Tatoud, M.J. O'Hare, J.R. Masters, D.L. Hudson, A conditionally immortalized cell line model for the study of prostatic epithelial cell differentiation, Differentiation 75 (2007) 735 35-48.

14] G. Gu, J. Yuan, M. Wills, S. Kasper, Prostate cancer cells with stem 737 cell characteristics reconstitute the original human tumor in vivo, 738 Cancer Res. 67 (2007) 4807-4815.

[15] J. Miki, B. Furusato, H. Li, Y. Gu, H. Takahashi, S. Egawa, I.A. Sesterhenn, 740 D.G. McLeod, S. Srivastava, J.S. Rhim, Identification of putative stem 741 cell markers, CD133 and CXCR4, in hTERT-immortalized primary $\quad 742$ nonmalignant and malignant tumor-derived human prostate $\quad 743$ epithelial cell lines and in prostate cancer specimens, Cancer Res. 67744 (2007) 3153-3161.

[16] H. Li, J. Zhou, J. Miki, B. Furusato, Y. Gu, S. Srivastava, D.G. McLeod, 746 J.C. Vogel, J.S. Rhim, Telomerase immortalized non-malignant $\quad 747$ human prostate epithelial cells retain the properties of 748 multipotent stem cells, Exp. Cell Res. 314 (2008) 92-102. 749

[17] E. Ferrandis, J. Da Silva, G. Riou, J. Bénard, Coactivation of the 750 MDR1 and MYCN genes in human neuroblastoma cells during the 751 metastatic process in the nude mouse, Cancer Res. 54 (1994) 752 2256-2261.

[18] W.W. Kao, D.J. Prockop, Proline analogue removes fibroblasts 754 from cultured mixed cell populations, Nature 266 (1977) 63-66. 755

[19] K. Fizazi, J. Yang, S. Peleg, C.R. Sikes, E.L. Kreimann, D. Daliani, 756 M. Olive, K.A. Raymond, T.J. Janus, C.J. Logothetis, G. Karsenty, N. 757 M. Navone, Prostate cancer cells-osteoblast interaction shifts $\quad 758$ expression of growth/survival-related genes in prostate cancer 759 and reduces expression of osteoprotegerin in osteoblasts, Clin. $\quad 760$ Cancer Res. 9 (2003) 2587-2597.

[20] Z.P. Pavelic, H.K. Slocum, Y.M. Rustum, P.J. Creaven, N.J. Nowak, 762 C. Karakousis, H. Takita, A. Mittelman, Growth of cell colonies in 763 soft agar from biopsies of different human solid tumors, Cancer 764 Res. 40 (1980) 4151-4158.

[21] M. Eura, K. Chikamatsu, F. Katsura, A. Obata, Y. Sobao, M. Takiguchi, 766 Y.Song, E. Appella, T.L. Whiteside, A.B. DeLeo, A wild-type sequence 767 p53 peptide presented by HLA-A24 induces cytotoxic T 768 lymphocytes that recognize squamous cell carcinomas of the head 769 and neck, Clin. Cancer Res. 6 (2000) 979-986. 770

[22] J. Couturier, B. Dutrillaux, Conservation of replication chronology 771 of homologous chromosome bands between four species of the 772 genus Cebus and man, Cytogenet. Cell Genet. 29 (1981) 233-240. 773

[23] K. Fizazi, C.R. Sikes, J. Kim, J. Yang, L.A. Martinez, M.C. Olive, C.J. 774 Logothetis, N.M. Navone, High efficacy of docetaxel with and $\quad 775$ without androgen deprivation and estramustine in preclinical $\quad 776$ models of advanced prostate cancer, Anticancer Res. 24 (2004) $\quad 777$ 2897-2903. 
[24] C.M. Counter, W.C. Hahn, W. Wei, S.D. Caddle, R.L. Beijersbergen, P.M. Lansdorp, J.M. Sedivy, R.A. Weinberg, Dissociation among in vitro telomerase activity, telomere maintenance, and cellular immortalization, Proc. Natl Acad. Sci. USA 95 (1998) 14723-14728.

[25] Z. Jiang, B.A. Woda, K.L. Rock, Y. Xu Test, Am. J. Surg. Pathol. 25 (2001) 1397-1404.

[26] S. Zha, S. Ferdinandusse, S. Denis, R.J. Wanders, C.M. Ewing, J. Luo, A.M. De Marzo, W.B. Isaacs, Alpha-methylacyl-CoA racemase as an androgen-independent growth modifier in prostate cancer, Cancer Res. 63 (2003) 7365-7376.

[27] M.J. Burger, M.A. Tebay, P.A. Keith, H.M. Samaratunga, J. Clements, M.F. Lavin, R.A. Gardiner, Expression analysis of delta-catenin and prostate-specific membrane antigen: their potential as diagnostic markers for prostate cancer, Int. J. Cancer 100 (2002) 228-237.

[28] L.W. Chung, A. Baseman, V. Assikis, H.E. Zhau HE, Molecular insights into prostate cancer progression: the missing link of tumor Microenvironment, J. Urol. 173 (2005) 10-20.

[29] M. Boiani, H.R. Scholer, Regulatory networks in embryo-derived pluripotent stem cells, Nat. Rev. Mol. Cell Biol. 6 (2005) 872-884.

[30] P.A. Beachy, S.S. Karhadkar, D.M. Berman, Tissue repair and stem cell renewal in carcinogenesis, Nature 432 (2004) 324-331.

[31] I.V. Litvinov, D.J. Vander Griend, Y. Xu, L. Antony, S.L. Dalrymple, J. T. Isaacs, Low-calcium serum-free defined medium selects for growth of normal prostatic epithelial stem cells, Cancer Res. 66 (2006) 8598-8607.

[32] J. Shou, S. Ross, H. Koeppen, F.J. de Sauvage, W.Q. Gao, Dynamics of notch expression during murine prostate development and tumorigenesis, Cancer Res. 61 (2001) 7291-7297.

[33] L.E. Pascal, A.J. Oudes, T.W. Petersen, Y.A. Goo, L.S. Walashek, L.D. True, A.Y. Liu, Molecular and cellular characterization of ABCG2 in the prostate, BMC Urol. 6 (2007) 6.

[34] D. Lequin, K. Fizazi, S. Toujani, S. Souquère, M.C. Mathieu, P. Hainaut, A. Bernheim, F. Praz, P. Busson, Biological characterization of two xenografts derived from human CUPs (carcinomas of unknown primary), BMC Cancer 7 (2007) 225.

[35] N.M. Navone, P. Troncoso, L.L. Pisters, T.L. Goodrow, J.L. Palmer, W.W. Nichols, A.C. von Eschenbach, C.J. Conti, p53 protein accumulation and gene mutation in the progression of human prostate carcinoma, J. Natl Cancer Inst. 85 (1993) 1657-1669.

[36] N.M. Navone, M.E. Labate, P. Troncoso, L.L. Pisters, C.J. Conti, A.C. von Eschenbach, C.J. Logothetis, p53 mutations in prostate cancer bone metastases suggest that selected p53 mutants in the primary site define foci with metastatic potential, J. Urol. 161 (1999) 304-308.
[37] Z. Storchova, C. Kuffer, The consequences of tetraploidy and 823 aneuploidy, J. Cell Sci. 121 (2008) 3859-3866. 824

[38] P.R. Andreassen, O.D. Lohez, F.B. Lacroix, R.L. Margolis, Tetraploid 825 state induces p53-dependent arrest of nontransformed 826 mammalian cells in G1, Mol. Biol. Cell 12 (2001) 1315-1328. 827

[39] M.S. Wicha, S. Liu, G. Dontu, Cancer stem cells: an old idea-a 828 paradigm shift, Cancer Res. 66 (2006) 1883-1890. 829

[40] L.L. Campbell, K. Polyak, Breast tumor heterogeneity: Cancer stem 830 cells or clonal evolution? Cell Cycle 6 (2007) 2332-2338. 831

[41] J.M. Adams, A. Strasser, Is tumor growth sustained by rare cancer 832 stem cells or dominant clones? Cancer Res. 68 (2008) 4018-4021. 833

[42] P. Sanchez, A.M. Hernández, B. Stecca, A.J. Kahler, A.M. DeGueme, 834 A. Barrett, M. Beyna, M.W. Datta, S. Datta, A. Ruiz, i Altaba, 835 Inhibition of prostate cancer proliferation by interference with 836 Sonic Hedgehog-GLI1 signaling, Proc. Natl Acad. Sci. USA 101837 (2004) 12561-12566.

[43] S.S. Karhadkar, G.S. Bova, N. Abdallah, S. Dhara, D. Gardner, A. Maitra, J.T. Isaacs, D.M. Berman, P.A. Beachy, Hedgehog signalling in prostate regeneration, neoplasia and metastasis, 841 Nature 431 (2004) 707-712.

[44] T. Sheng, C. Li, X. Zhang, S. Chi, N. He, K. Chen, F. McCormick, 843 Z. Gatalica, J. Xie, Activation of the hedgehog pathway in 844 advanced prostate cancer, Mol. Cancer 3 (2004) 29.

[45] B.Y. Chen, J.Y. Liu, H.H. Chang, C.P. Chang, W.Y. Lo, W.H. Kuo, C.R. 846 Yang, D.P. Lin, Hedgehog is involved in prostate basal cell $\quad 847$ hyperplasia formation and its progressing towards 848 tumorigenesis, Biochem. Biophys. Res. Commun. 357 (2007) 849 1084-1089.

[46] S. Thiyagarajan, N. Bhatia, S. Reagan-Shaw, D. Cozma, A. Thomas-Tikhonenko, N. Ahmad, V.S. Spiegelman, Role of GLI2 852 transcription factor in growth and tumorigenicity of prostate 853 cells, Cancer Res. 67 (2007) 10642-10646. 854

[47] M. Zayzafoon, S.A. Abdulkadir, J.M. McDonald, Notch signaling 855 and ERK activation are important for the osteomimetic properties 856 of prostate cancer bone metastatic cell lines, J. Biol. Chem. $279 \quad 857$ (2004) 3662-3670.

[48] N. Scorey, S.P. Fraser, P. Patel, C. Pridgeon, M.J. Dallman, M.B. 859 Djamgoz, Notch signalling and voltage-gated Na1 channel activity 860 in human prostate cancer cells: independent modulation of in 861 vitro motility, Prostate Cancer Prostatic Dis. 9 (2006) 399-406. 862

[49] Y.C. Chen, H.S. Hsu, Y.W. Chen, T.H. Tsai, C.K. How, C.Y. Wang, S.C. 863 Hung, Y.L. Chang, M.L. Tsai, Y.Y. Lee, H.H. Ku, S.H. Chiou, Oct-4 864 expression maintained cancer stem-like properties in lung 865 cancer-derived CD133-positive cells, PLoS ONE 3 (2008) e2637. 866 